\title{
Review
}

\section{Unsteady exergy analysis for a recycle and recovery machine}

\author{
Berkah Fajar TK *, Delta Panca N, Gunawan Wicaksono \\ Department of Mechanical Engineering, Diponegoro University, Prof.Sudharto, SH. Street, Tembalang-Semarang \\ 50275, Indonesia
}

\section{A R T I C L E I N F O}

\section{Article history:}

Received 28 September 2016

Received in revised form 6

September 2017

Accepted 1 October 2017

Available online 12 October 2017

Keywords:

Refrigeration

Exergy

Exergy destruction

Energy

Entropy

\begin{abstract}
A B S T R A C T
Machine $2 \mathrm{R}$ is necessary in order to avoid the release of refrigerant during the repair of an air conditioning machine. The main goals of this paper are to determine the rate of exergy transfer, the rate of exergy destruction and the rate of exergy change in the compressor, condenser, oil separator and $2 \mathrm{R}$ machine. This study also determines the performance of the $2 \mathrm{R}$ machine. Pressure, temperature and mass of the refrigerant were measured every 0.5 minutes for 10 minutes. In conclusion, the results of this analysis show that the rate of destruction exergy in the compressor is $59.98 \%$, and $25.37 \%$ in the condenser. The value of the Residual Trapped Refrigerant (RTR) of recycling and recovery machine meets the AHRI standard, that is, 34 grams, and the value of the Refrigerant Loss (RL) complies with the AHRI standard, which is 10 grams, while its performance is $91.2 \%$.
\end{abstract}

๑) 2017 Elsevier Ltd and IIR. All rights reserved.

\section{Analyse de l'exergie instable pour une machine de recyclage et de récupération}

Mots clés : Froid ; Exergie ; Destruction exergétique ; Énergie ; Entropie

\section{Introduction}

There are now two global environmental issues that are considered the most threatening life on earth: the depletion of the ozone layer and global warming. Damage to the ozone layer is caused by various synthetic substances that are used in many industrial applications, which include the development of refrigeration technology. One of the refrigerants used in vapor compression refrigeration system is refrigerant $\mathrm{R} 22$, which has ODP and WGP high enough so that the necessary tools for recovery and recycle of the refrigerant contained in the

\footnotetext{
* Corresponding author. Department of Mechanical Engineering, Diponegoro University, Prof.Sudharto, SH. Street, Tembalang-Semarang 50275, Indonesia.
}

E-mail address: fajarberkah10@gmail.com (B. Fajar TK).

https://doi.org/10.1016/j.ijrefrig.2017.10.002

0140-7007/@ 2017 Elsevier Ltd and IIR. All rights reserved. 


\begin{tabular}{|c|c|}
\hline \multicolumn{2}{|l|}{ Nomenclature } \\
\hline e & Specific exergy $\left[\mathrm{Jkg}^{-1}\right]$ \\
\hline $\mathrm{E}$ & Energy [J] \\
\hline ED & Exergy destruction [W] \\
\hline Ex & Exergy (J) \\
\hline $\mathrm{h}$ & Specific enthalpy $\left[\mathrm{Jkg}^{-1}\right]$ \\
\hline$\dot{m}$ & Mass flow rate $\left[\mathrm{kgs}^{-1}\right]$ \\
\hline M & Mass [g] \\
\hline$\dot{Q}$ & Rate of energy transfer by heat [W] \\
\hline$R L$ & Refrigerant Loss [g] \\
\hline RTR & Residual Trapped Refrigerant [g] \\
\hline s & Specific entropy $\left[\mathrm{Jkg}^{-1} \mathrm{~K}^{-1}\right]$ \\
\hline$\dot{S}$ & Entropy generation $\left[\mathrm{Js}^{-1} \mathrm{~K}^{-1}\right]$ \\
\hline $\mathrm{T}$ & Temperature (K) \\
\hline$\dot{\mathrm{W}}$ & Rate of energy transfer by work [W] \\
\hline \multicolumn{2}{|l|}{ Subscripts } \\
\hline 0 & Reference \\
\hline a & Initial mass of refrigerant \\
\hline compressor & Compressor \\
\hline condenser & Condenser \\
\hline CV & Control Volume \\
\hline e & Exit \\
\hline $\mathrm{fe}$ & Flow of exergy exit \\
\hline fi & Flow of exergy inlet \\
\hline $\begin{array}{l}\text { Finale tank } \\
\text { gen }\end{array}$ & $\begin{array}{l}\text { Final tank } \\
\text { generation }\end{array}$ \\
\hline i & Inlet \\
\hline Initial tank & Initial tank \\
\hline Oil separator & Oil separator \\
\hline $\begin{array}{l}r \\
\text { total }\end{array}$ & $\begin{array}{l}\text { Recovered of refrigerant } \\
\text { total }\end{array}$ \\
\hline Totalrefrigerant & Total refrigerant \\
\hline
\end{tabular}

refrigeration system is not directly released into the environment. A recycle and recovery machine is used to recycle and move the refrigerant contained in a refrigeration system into its storage tank, so that the refrigerant is not released into the environment. The refrigerant that has been in the recycling can be reused or destroyed. The energy consumption of an engine is part of the most critical parameters in the agenda of future strategies for several industries and a number of commercial sectors. The demands of high efficiency and even small optimizations in the system performance can result in cost savings and significant energy savings, and thus, increasing profits. Exergy analysis is a method that uses the conservation of mass and conservation of energy principles together with the second law of thermodynamics for the design and analysis of energy systems. Exergy analysis results can effectively reveal the performance and improve the potential of each component in the refrigeration system (Guiyin Fang et al., 2004).

Many studies have been conducted regarding exergy analysis on a refrigeration system or analysis on unsteady exergy. Research on energy and exergy has been conducted by Neera Jain and Alleyne (2015), Alptug Yataganbaba et al. (2015), Miguel Padilla et al. (2010), Guiyin Fang et al. (2004), and Halimeh Aghaei Zoori et al. (2013). Alptug Yataganbaba et al. (2015) conducted analysis of the low GWP refrigerants R1234yf and R1234ze as replacements for $\mathrm{R} 134 \mathrm{a}$ in a two evaporator VCRS. A mathematical computational model was developed for performing the exergy analysis of the system using EES software. The highest exergy efficiencies are obtained with R1234ze and R134a. Miguel Padilla et al. (2010) conducted an exergy analysis of the impact of direct replacement (retrofit) of R12 with the zeotropic mixture R413A on the performance of a domestic vaporcompression refrigeration system originally designed to work with R12. Guiyin Fang et al. (2004) conducted exergy analysis of the refrigeration system in ice storage operating mode to compare with that of the refrigeration system in air conditioning operating mode. These studies used a computational model related to the exergy loss amount and loss rate was developed in each component of the refrigeration cycle loop to compare the results of analysis exergy of the cooling system in the ice storage operation mode with the cooling system operated in air conditioning mode. Based on the above literature, it is important to analyze exergy as to the efficiency and operation in order to achieve design optimization to determine the source of the largest exergy destruction. In this study, the analysis was applied to the unsteady exergy analysis for a recycle and recovery machine with refrigerant $\mathrm{R} 22$.

\section{System description}

Fig. 1a shows a $2 \mathrm{R}$ machine testing equipment which is linked to an air-conditioner of $0.5 \mathrm{HP}$ capacity and $500 \mathrm{~g}$ refrigerant content. The $2 \mathrm{R}$ machine consists of a compressor of $0.25 \mathrm{HP}$, two pieces of filter drier and one piece of oil separator. To measure the refrigerant flow, IC LM35 NI DAQ a pressure gauge and a vacuum gauge are used as shown in Fig. 1, where $T$ stands for the thermocouples and P stands for the pressure and vacuum gauge. The refrigerant mass was weighed by a digital scale. A refrigerant storage tank with digital scales enables the mass of refrigerant to be measured every 0.5 minutes. All the measurements were collected every 0.5 seconds. The temperature of the refrigerant was measured and collected in a computer using data acquisition (DAQ NI 6000). The recovery process took 10 minutes.

Fig. 1b shows a T-s diagram of the recycle and recovery machine. If irreversibilities within the condenser and the oil separator are neglected, there are no frictional pressure drops, and the refrigerant flows at constant pressure through the condenser. If compression occurs without irreversibilities, then stray heat transfer to the surroundings is also neglected. The compression process is isentropic. Using these considerations, the recycle and recovery machine labeled 1-2-3 on the T-s diagram are as shown in Fig. 1b (Pasek et al., 2004).

The objectives of this study are as follow:

1. To determine the rate of exergy transfer in the oil separator, the compressor, the condenser and in the $2 \mathrm{R}$ machine

2. To determine the rate of exergy destruction in the oil separator, the compressor, the condenser and in the $2 \mathrm{R}$ machine

3. To determine the rate of exergy change in the oil separator, the compressor, the condenser in the $2 \mathrm{R}$ machine

4. To determine the performance of $2 \mathrm{R}$ machine 


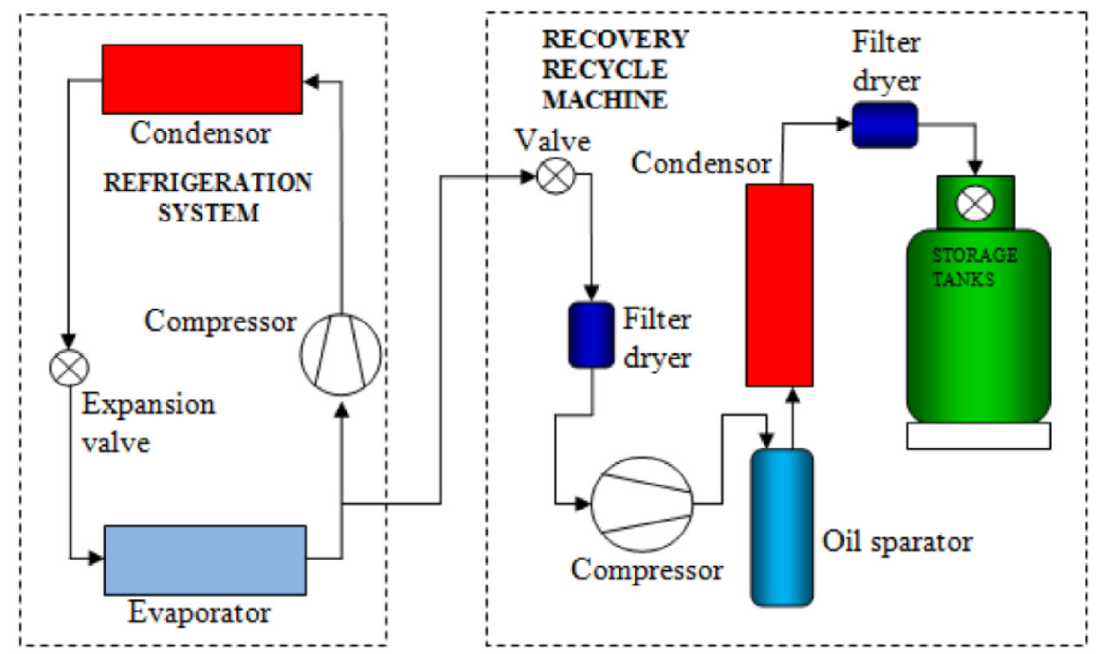

(a)

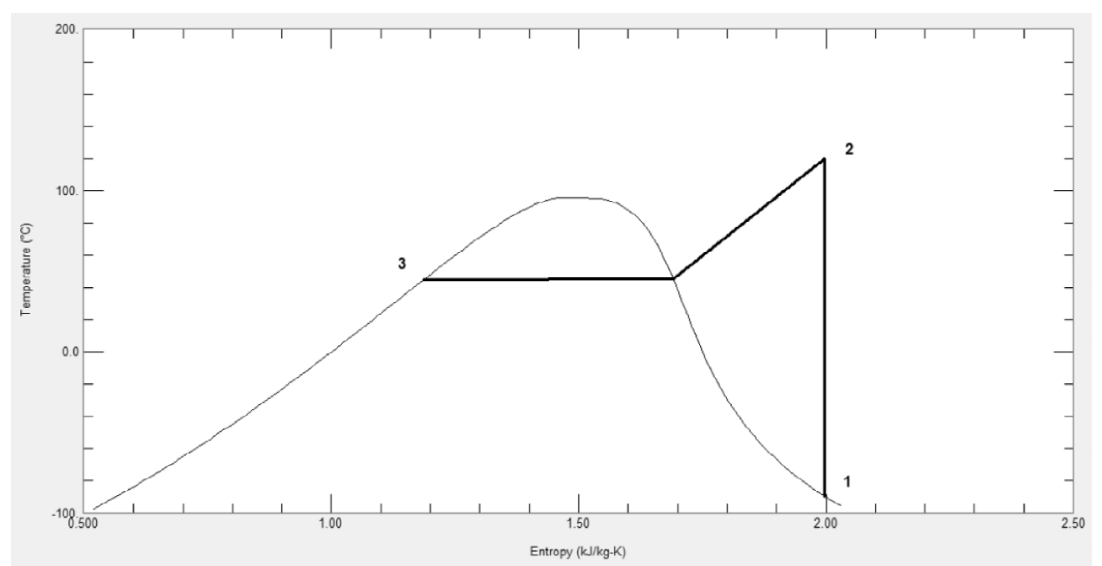

(b)

Fig. 1 - (a) Scheme of operation and (b) Ideal T-s diagram for a recycle and recovery machine.

5. To determine the real T-s diagram of the recycle and recovery machine to improve the design process of the $2 \mathrm{R}$ machine

\section{Mathematical model}

The $2 \mathrm{R}$ machine was analyzed based on energy and exergy flow that enters and exits the system. The status of refrigerant flow in the $2 \mathrm{R}$ machine was changing with the time. Therefore, this analysis must be performed using an unsteady analysis (Moran and Shapiro, 2006).

\subsection{Energy and exergy analysis}

An energy analysis is based on the first law of thermodynamics. The analysis only provides information about energy that comes in, useful energy and wasted energy. The analysis does not provide information about the possible wasted energy that can still be used. Using exergy analysis, we can know the incoming, useful and damaged exergy which provides more complete information. This analysis combines the first and second laws of thermodynamics. Exergy analysis is the optimized useful energy which is a convenient method to design a system and represents the methodology to manage the energy resources in most industrial processes.

On the recycle and recovery machine there are rates of energy transfer by working into the compressor; the rate of energy transfer in by mass and out of the system, and the rate of energy transfer by heat out from recycle and recovery machine. It is assumed that in the calculation of the energy analysis on the recycle and recovery machine, kinetic energy and potential energy are negligible. Equation 1 shows the energy balance equation for the recycle and recovery machine (Cengel and Boles, 2006). Equation 2 shows the calculated energy in the form of work into the system from the compressor in the recovery and recycle machine (Cengel and Boles, 2006). Equation 3 shows the calculated energy through heat coming out of the condenser and the oil separator in the recovery and recycling machine (Moran and Shapiro, 2006). The energy flow of the oil is too small compared to the 
flow of refrigerant, therefore the energy flow of oil is neglected.

$\frac{\mathrm{dE}}{\mathrm{dt}}=\dot{\mathrm{Q}}_{\mathrm{cv}}-\dot{\mathrm{W}}_{\mathrm{cv}}+\sum_{\mathrm{i}} \dot{\mathrm{m}}_{\mathrm{i}}\left(\mathrm{h}_{\mathrm{i}}\right)-\sum_{e} \dot{\mathrm{m}}_{\mathrm{e}}\left(\mathrm{h}_{\mathrm{e}}\right)$

$\dot{\mathrm{W}}_{c v}=\sum_{i} \dot{m}_{i}\left(h_{i}\right)-\sum_{e} \dot{m}_{e}\left(h_{e}\right)$

$\dot{\mathrm{Q}}_{\mathrm{cv}}=\sum_{e} \dot{m}_{e}\left(h_{e}\right)-\sum_{i} \dot{m}_{i}\left(h_{\mathrm{i}}\right)$

where:

- $\mathrm{dEcv} / \mathrm{dt}=$ Rate of energy change in control volume (W)

- $\dot{\mathrm{Q}}_{\mathrm{cv}}=$ Rate of energy transfer by heat (W)

- $\dot{\mathrm{W}}_{\mathrm{cv}}=$ Rate of energy transfer by work (W)

- $\sum_{\mathrm{i}} \dot{\mathrm{m}}_{\mathrm{i}}\left(\mathrm{h}_{\mathrm{i}}\right)=$ Rate of energy transfer in by mass (W)

- $\sum_{\mathrm{e}} \dot{\mathrm{m}}_{\mathrm{e}}\left(\mathrm{h}_{\mathrm{e}}\right)=$ Rate of energy transfer out by mass $(\mathrm{W})$

Total exergy can be presented by the potential exergy (Ept), kinetic exergy (Ekn), chemical exergy (Ech) and physical exergy (Eph) (Bejan et al., 1996). Because of recycling and recovery in the machine, no combustion occurs so the chemical exergy can be neglected. The potential exergy and kinetic exergy are also negligible. An exergy transfer at the boundary of a control volume can be associated with a stream of material or energy transfer by heat or work. A common form of exergy balance for the control volume system that involves some inlet and outlet flows of matter and energy is given by Moran and Shapiro (2006). Balance exergy in recycle and recovery machine, balance exergy in compressor, balance exergy in oil separator and balance exergy in condenser can be determined by Equations (4)-(7).

- Balance exergy in recycle and recovery machine

$\frac{d E x_{c v}}{d t}=\sum_{j}\left(1-\frac{T_{0}}{T_{j}}\right) \dot{Q}_{j}-\left(\dot{W}_{c v}\right)+\sum_{i} \dot{m}_{i} e_{f i}-\sum_{e} \dot{m}_{e} e_{f e}-\dot{E D}$

- Balance exergy in compressor

$\frac{d E x_{c v}}{d t}=-\left(\dot{\mathrm{W}}_{\mathrm{cv}}\right)+\sum_{\mathrm{i}} \dot{\mathrm{m}}_{\mathrm{i}} \mathrm{e}_{\mathrm{fi}}-\sum_{\mathrm{e}} \dot{\mathrm{m}}_{\mathrm{e}} \mathrm{e}_{\mathrm{fe}}-\mathrm{ED}$

- Balance exergy in oil separator

$\frac{d E x_{\mathrm{cv}}}{\mathrm{dt}}=\sum_{\mathrm{i}} \dot{\mathrm{m}}_{\mathrm{i}} \mathrm{e}_{\mathrm{fi}}-\sum_{e} \dot{\mathrm{m}}_{\mathrm{e}} \mathrm{e}_{\mathrm{fe}}-\mathrm{ED}$

- Balance exergy in condenser

$\frac{\mathrm{dEx}_{\mathrm{cv}}}{\mathrm{dt}}=\sum_{\mathrm{j}}\left(1-\frac{\mathrm{T}_{0}}{\mathrm{~T}_{\mathrm{j}}}\right) \dot{\mathrm{Q}}_{\mathrm{j}}+\sum_{\mathrm{i}} \dot{\mathrm{m}}_{\mathrm{i}} \mathrm{e}_{\mathrm{fi}}-\sum_{\mathrm{e}} \dot{\mathrm{m}}_{\mathrm{e}} \mathrm{e}_{\mathrm{fe}}-\mathrm{ED}$

where:

- $\dot{m}=$ Mass flow rate $\left(\mathrm{kgs}^{-1}\right)$

- $\mathrm{T}_{0}=$ Reference temperature $(\mathrm{K})$
- $\mathrm{T}_{\mathrm{j}}=$ Source temperature $(\mathrm{K})$

- $\Sigma_{j}\left(1-\mathrm{T}_{0} / \mathrm{T}_{\mathrm{j}}\right) \dot{\mathrm{Q}}_{j}=$ Exergy transfer accompanying heat $(\mathrm{W})$

- $\mathrm{dExcv} / \mathrm{dt}=$ Rate of exergy change in control volume (W)

- $\dot{\mathrm{W}}_{\mathrm{cv}}=$ Exergy transfer accompanying work (W)

$-\sum_{\mathrm{i}} \dot{\mathrm{m}}_{\mathrm{i}} \mathrm{e}_{\mathrm{fi}}=$ Exergy transfer in accompanying mass (W)

- $\sum_{e} \dot{\mathrm{m}}_{\mathrm{e}} \mathrm{e}_{\mathrm{fe}}=$ Exergy transfer out accompanying mass (W)

- ED = Exergy destruction (W)

Generally, the entropy balance for the control volume for any process can be expressed as Equation 8 (Cengel and Boles, 2006).

The heat energy coming out of the compressor and oil separator is calculated using the calculation of natural convection in the outer surface of the compressor and oil separator. Entropy generation in a compressor, entropy generation in an oil separator and entropy generation in a condenser can be determined by Equations (8)-(10) (Holman, 1997).

- Entropy generation in a compressor

$\dot{\mathrm{S}}_{\text {gen }}=\frac{\mathrm{dS}}{\mathrm{dt}}+\sum \dot{\mathrm{m}}_{\mathrm{e}} \mathrm{S}_{\mathrm{e}}-\sum \dot{\mathrm{m}}_{\mathrm{i}} \mathrm{S}_{\mathrm{i}}-\sum_{\mathrm{j}} \frac{\dot{\mathrm{Q}}_{\mathrm{j}}}{\mathrm{T}_{\mathrm{j}}}$

- Entropy generation in an oil separator

$\dot{\mathrm{S}}_{\text {gen }}=\frac{\mathrm{dS}_{\mathrm{cv}}}{\mathrm{dt}}+\sum \dot{\mathrm{m}}_{\mathrm{e}} \mathrm{S}_{\mathrm{e}}-\sum \dot{\mathrm{m}}_{\mathrm{i}} \mathrm{S}_{\mathrm{i}}-\sum_{\mathrm{j}} \frac{\dot{\mathrm{Q}}_{\mathrm{j}}}{\mathrm{T}_{\mathrm{j}}}$

- Entropy generation in a condenser

$\dot{\mathrm{S}}_{\mathrm{gen}}=\frac{\mathrm{dS} \mathrm{sv}_{\mathrm{d}}}{\mathrm{dt}}+\sum \dot{\mathrm{m}}_{\mathrm{e}} \mathrm{S}_{\mathrm{e}}-\sum \dot{\mathrm{m}}_{\mathrm{i}} \mathrm{s}_{\mathrm{i}}-\sum_{\mathrm{j}} \frac{\dot{\mathrm{Q}}_{\mathrm{j}}}{\mathrm{T}_{\mathrm{j}}}$

where:

$-\frac{d S_{c v}}{d t}=$ Change of entropy of the system $\left(\mathrm{JK}^{-1}\right)$

- $\sum \dot{m}_{\mathrm{i}} \mathrm{s}_{\mathrm{i}}=$ Transfer entropy by mass flow rate $\left(\mathrm{Js}^{-1} \mathrm{~K}^{-1}\right)$

$-\sum \dot{m}_{e} \mathrm{~s}_{e}=$ Transfer entropy by mass flow rate $\left(\mathrm{Js}^{-1} \mathrm{~K}^{-1}\right)$

$-\Sigma_{j} \frac{\dot{Q}_{j}}{T_{j}}=$ Transfer entropy by heat flow rate $\left(\mathrm{Js}^{-1} \mathrm{~K}^{-1}\right)$

$-\dot{S}_{g e n}=$ The entropy generation $\left(\mathrm{Js}^{-1} \mathrm{~K}^{-1}\right)$

To determine the rate of change of entropy in the control volume at time $(\mathrm{t})$, it is assumed that the entropy in the control volume is the average entropy in and out. The average entropy in the control volume can be determined using the following equation :

$\overline{S_{C V}(t)}=\frac{S_{i}(t)+S_{e}(t)}{2}$

Therefore, the rate of change of entropy in the control volume can be calculated by differentiating Equation 11 with respect to time.

The irreversibility rate can be estimated from the following equation (Cengel and Boles, 2006): 
$\mathrm{ED}=\mathrm{T}_{0} \dot{\mathrm{S}}_{\text {gen }}$

where:

- ED = Exergy destruction (W)

- $\mathrm{T}_{0}=$ Ambient termperature $(\mathrm{K})$

- $\dot{\mathrm{S}}_{\text {gen }}=$ Entropy generation $\left(\mathrm{Js}^{-1} \mathrm{~K}^{-1}\right)$

Total exergy destruction on the recycle and recovery machine can be expressed as Equation 13 (Guiyin Fang et al., 2004)

$E D_{\text {total }}=E D_{\text {compressor }}+E D_{\text {oil separator }}+E D_{\text {condenser }}$

where:

- $\mathrm{ED}_{\text {total }}=$ Total exergy destruction (W)

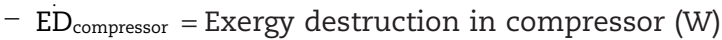

- EDoil separator $=$ Exergy destruction in oil separator (W)

- $\mathrm{ED}_{\text {condenser }}=$ Exergy destruction in condenser (W)

\subsection{Performance analysis}

Residual Trapped Refrigerant (RTR) is the refrigerant remaining in refrigerant recovery equipment and recovery/recycling equipment after refrigerant recovery of less than 50g (AHRI Standard 740-98, 2015), as given by:

$\mathrm{RTR}=\mathrm{M}_{\text {totalrefrigerant }}-\left(\mathrm{M}_{\text {initial tank }}-\mathrm{M}_{\text {finale tank }}\right)$

A Refrigerant Loss (RL) is the amount of refrigerant released into the environment during the process of recovery and recycle. According to AHRI Standard 740, total refrigerant loss shall be less than $3 \%$ of the total mass (AHRI Standard 740-98, 2015). RL is expressed by:

$R L=M_{a}-M_{\text {finale tank }}-R T R$

The performance of the recycle and recovery machine is obtained from the following formula:

Performance $=\frac{M_{r}}{M_{a}} \times 100 \%=\frac{M_{a}-R T R-R L}{M_{a}} \times 100 \%$ where:

$M_{r}=$ The mass of the recovered refrigerant (g)

- $M_{a}=$ The initial mass of refrigerant in the refrigeration system (g)

- RTR = Residual Trapped Refrigeran (g)

$-R L=$ Refrigerant Loss (g)

T-s chart obtained from actual data during the process of testing will be compared with T-s graph theory of the recycling and recovery of the machine.

\section{Result and discussion}

From Fig. 2, it can be seen that value exergy transfer accompanies work, exergy transfer in accompanies mass and exergy transfer out accompanying mass into the recycle and recovery machine decreases with increasing time. This was due to the mass flow rate of the recycle and recovery machine decreases with increasing time, because the value of work and mass is proportional to the mass flow rate. The rate exergy transfer accompanying heat from the recycle and recovery machine decreases with increasing time, this is due to the mass flow rate to the recycle and recovery machine decreases with increasing time since the value exergy accompanying heat is proportional to the mass flow rate. The minimum of exergy destruction is reached in seconds to 210 and increased again at second to 510. The temperature difference between the condenser to the ambient temperature is not much different that accompany exergy value of heat coming out of the recycling and recovery machine and has a low value. The rate of exergy change in recycling and recovery machine has a negative value, because there is a decrease of exergy in the recycling and recovery machine.

In the compressor, there is no rate of exergy transfer accompanying heat into or out of the compressor. From Fig 3, it can be seen that value exergy transfer accompanies work, exergy transfer in accompanying mass and exergy transfer out accompanying mass into the compressor decreases with increasing time was due to the mass flow rate of the recycle and recovery machine decreases with increasing time, because the value of work and mass is proportional to the mass flow rate. The exergy destruction on the compressor is similar to the

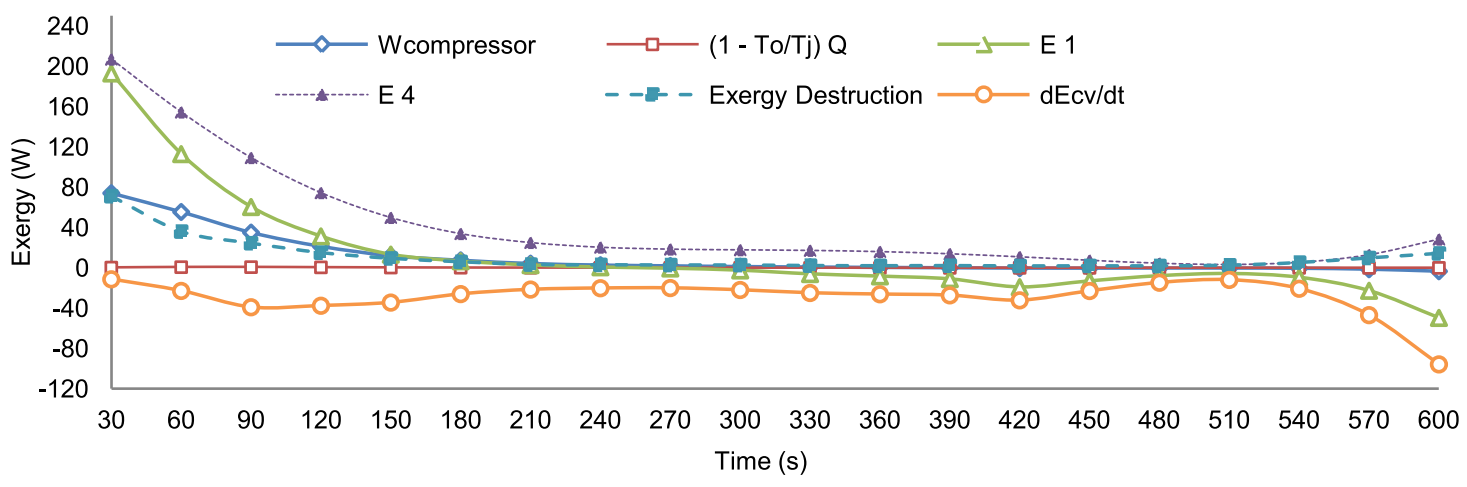

Fig. 2 - The exergy analysis in recycle and recovery machine. 


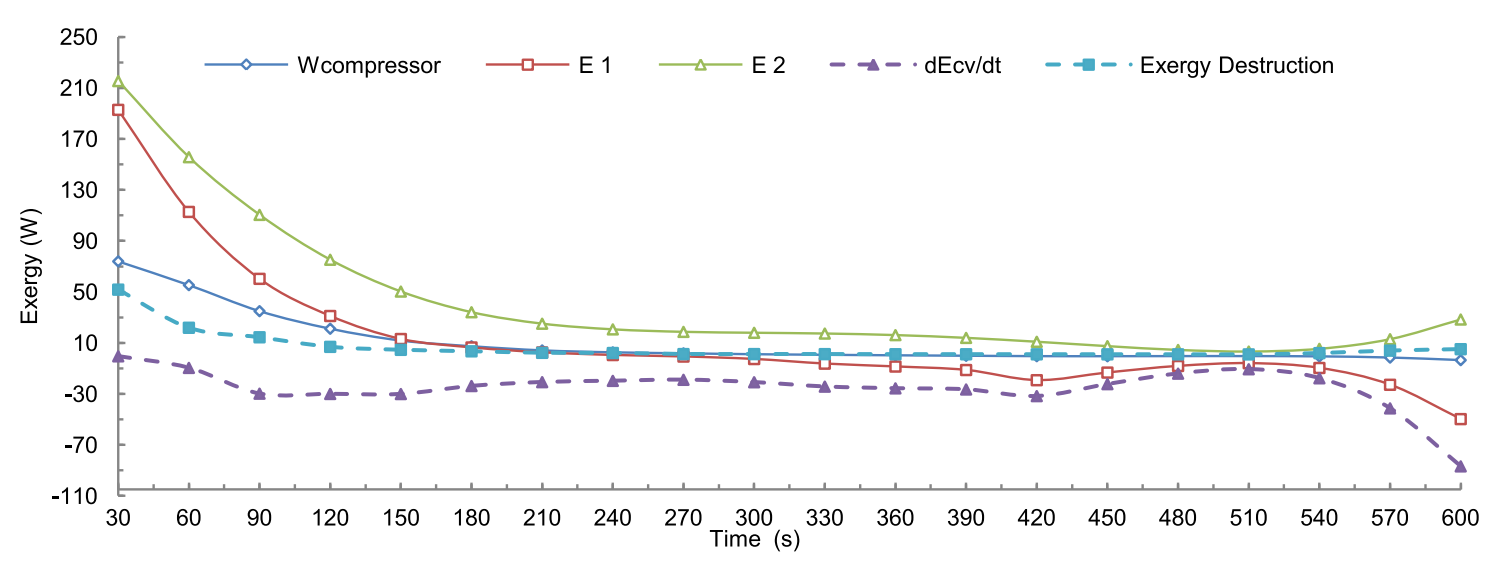

Fig. 3 - The exergy analysis in compressor.

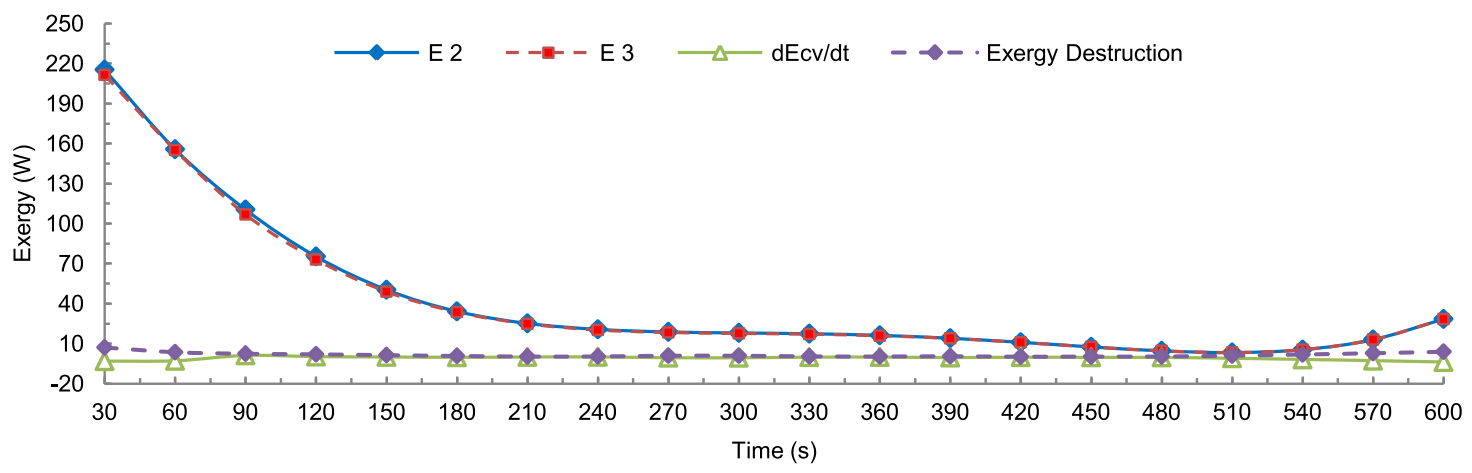

Fig. 4 - The exergy analysis in oil separator.

destruction of exergy in the $2 \mathrm{R}$ engine that the destruction of exergy reaches the minimum value of 210 seconds and will rise again in 510 seconds. This is due to the characteristic mass flow rate. The exergy flow rate coming out of the compressor is higher than the exergy flow coming into the compressor, due to the exergy work of the compressor. The rate of exergy change in compressor has a negative value, because there is a decrease of exergy in the compressor.

In the oil separator, there is no exergy transfer rate accompanying the heat and work into or out of the oil separator. Fig. 4 shows that the value of exergy transfer in accompanying mass and exergy transfer out accompanying mass into the oil separator decreases with increasing time was due to the mass flow rate of the recycle and recovery machine decreasing with increasing time, because the value of mass is proportional to the mass flow rate. The flow exergy rate enters the oil separator is equal to the exergy flow rate coming out the oil separator. The exergy destruction on oil separator is very small compared to the exergy destruction of the compressor, so that the exergy destruction on the oil separator can be ignored. The rate of exergy change in oil separator has a negative value, because there is a decrease of exergy in the oil separator.

In the condenser, there is no exergy transfer rate accompanying the work into or out of the condenser. From Fig. 5, the rate exergy transfer accompanying heat exit from the condenser decreases with increasing time. It happened due to the

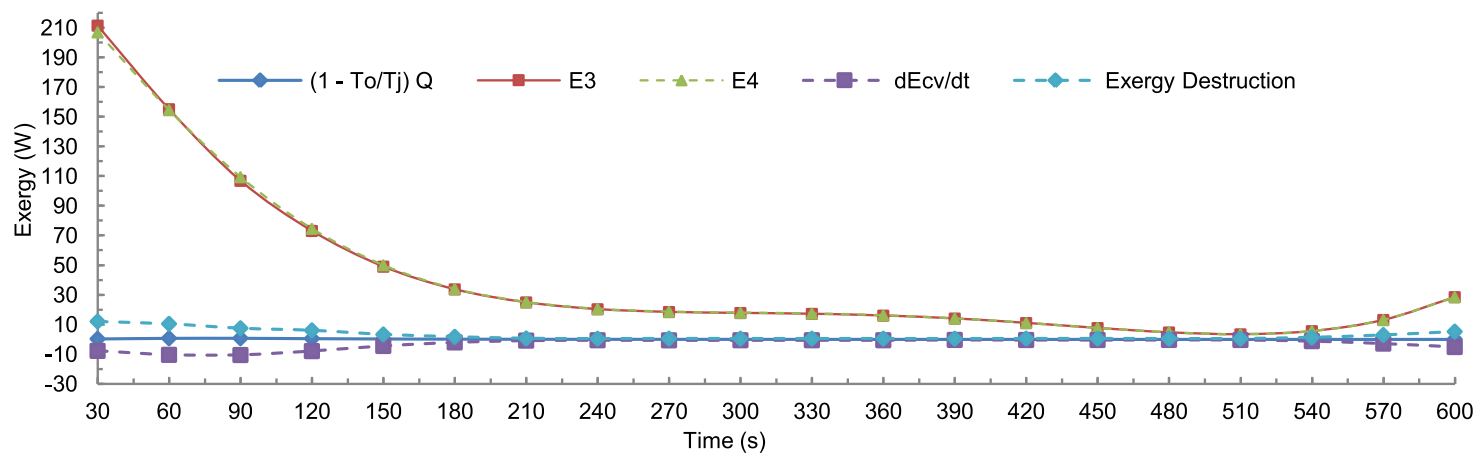

Fig. 5 - The exergy analysis in condenser. 


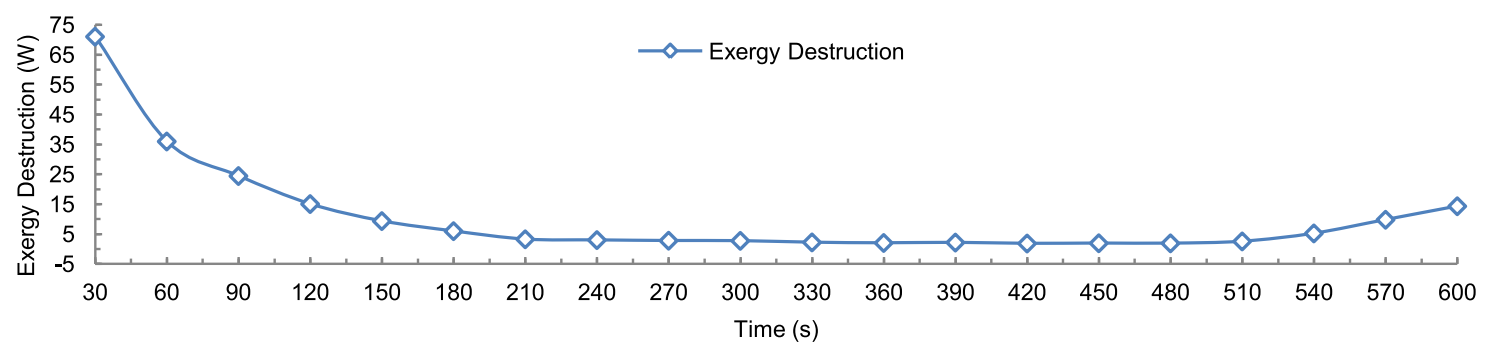

Fig. 6 - The exergy destruction in recycle and recovery machine.

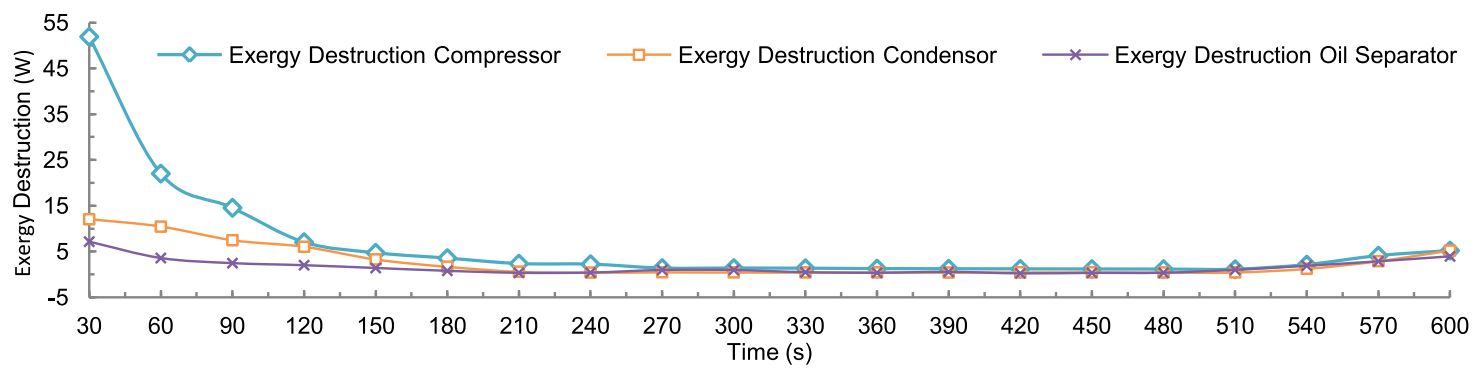

Fig. 7 - The exergy destruction in different components.

mass flow rate to the condenser decreases with increasing time since the value exergy accompanying heat is proportional to the mass flow rate. The value of exergy transfer in accompanying mass and exergy transfer out accompanying mass into the condenser decreases with increasing time due to the mass flow rate of the condenser decreasing with increasing time, because the value of mass is proportional to the mass flow rate. The rate of exergy change in the condenser has a negative value because there is a decrease of exergy in the condenser. The exergy destruction in the condenser is reached at 210 seconds and increases again at 510 seconds.

Fig. 6 shows the total value of the rate of destruction exergy which decreases significantly within 30 to 120 seconds, but from 120 to 180 seconds, the rate of exergy destruction does not really decline, while from 480 to 600 seconds the rate of exergy destruction increases slightly. Fig. 7 shows the value of the rate of exergy destruction on each component in the recycle and recovery machine. The exergy destruction at each component between 300 to 400 seconds is almost negligible, because the initial pressure of the refrigerant which enters the compressor from the refrigerator machine is still positive. For a while later, the pressure becomes negative, so that the exergy destruction at 300 to 400 seconds is minimal or can be neglected.
Exergy destruction contributor on a recycle and recovery machine with an average percentage of each minute is equal to $59.98 \%$ of the total exergy destruction that occurred in the compressor, $1464 \%$ of the total exergy destruction that occurred in the oil separator, and $25.37 \%$ of the total exergy destruction that occurred in the condenser. It seems that the exergy destruction rate in the compressor is the largest. This is due to the irreversible compression process which results in exergy destruction. The compressor with higher isentropic compression efficiency may reduce exergy loss, so screw or scroll compressors are usually used in the refrigeration system. With the exception exergy destruction in the compressor, the exergy destruction in the condenser is greater than that in the oil separator. The contribution in the condenser exergy loss accounts for irreversibilities associated with finite temperature differences. Reducing thermal resistance of heat transfer and the temperature difference in the heat transfer can decrease exergy destruction in the condenser.

From Fig. 8, it can be seen that high or low value of the rate of energy transfer by work is more influenced by the mass flow rate and pressure of the refrigerant, while the intensity of the rate of energy transfer by heat is more influenced by the mass flow rate and temperature of the refrigerant.

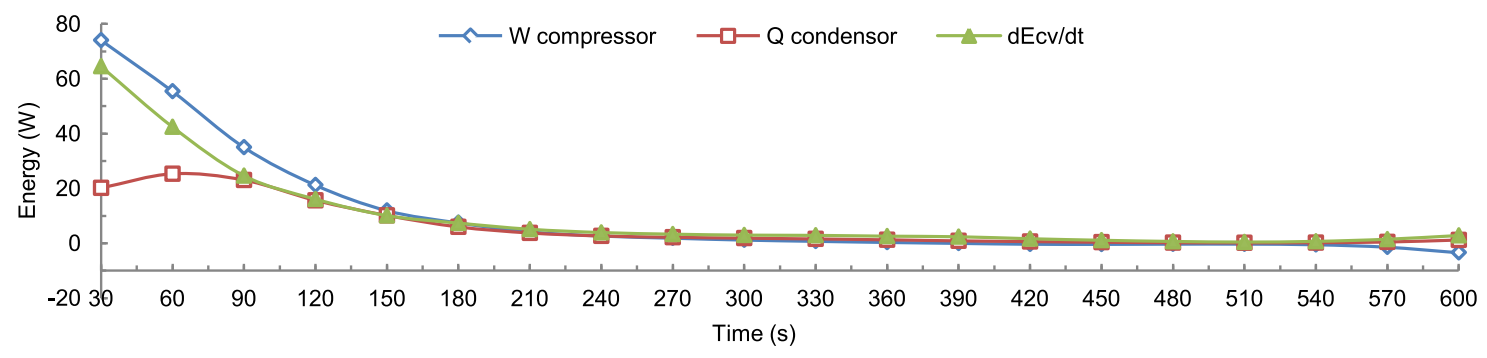

Fig. 8 - The energy analysis in the form of heat and work. 

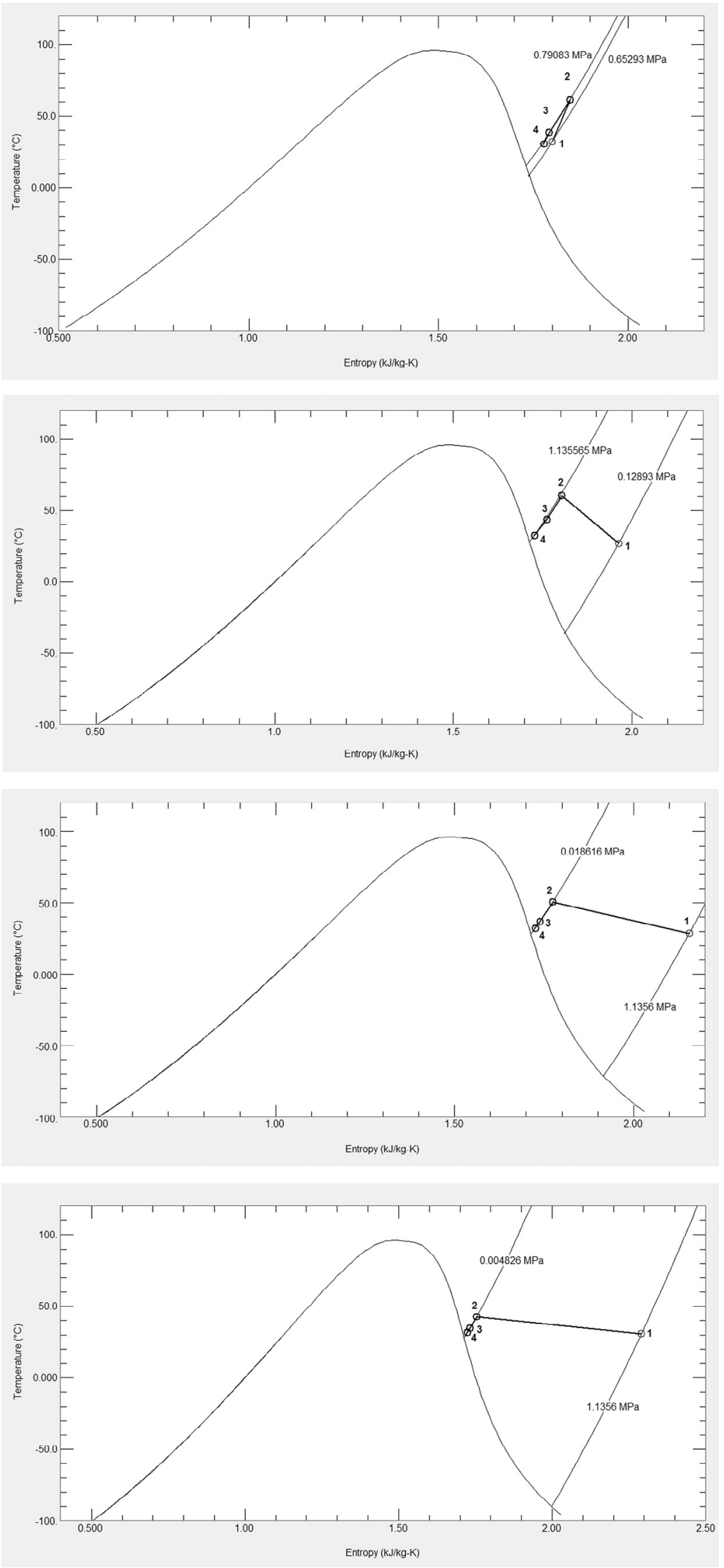

Fig. 9 - T-s diagram of the recycle and recovery machine in $0.5 ; 3.5 ; 6.5$; and 10 minutes. 
The value of RTR is $34 \mathrm{~g}$, while according to AHRI Standard 740 RTR value must be less than $50 \mathrm{~g}$ so that the recycle and recovery machine already compatible with the standard for Residual Trapped Refrigerant (RTR). For the calculation, the value of Refrigerant Loss (RL) obtained is $10 \mathrm{~g}$ while according to AHRI Standard 740, a large RL is $15 \mathrm{~g}$; so the recycle and recovery machine is already compatible with the standards for grades of Refrigerant Loss (RL). The performance of the recycle and recovery machine is equal to $92.1 \%$. From the results of experiment, the residual trap of refrigerant reached $50 \mathrm{~g}$ was at 50 seconds.

Fig. 9 shows T-s diagram for the machine in minutes of 0.5 ; 3.5; 6.4; and 10. It is known that from point 1 to point 2 process occurs in the compressor, a process that occurs in the compressor at 0.5 minutes that an increase in pressure and temperature and is followed by an increase in entropy that shows the irreversible process, whereas in 3.5 to 10 minutes, there are increase of pressure, temperature, and a decrease in the value of entropy. The decreasing of entropy is due to the rate of entropy change in the compressor. Point 2 to point 3 occurred in the oil separator, as seen from Fig. 9 that the phase refrigerant, when it passes through an oil separator is superheated. Point 3 to point 4 is a process that occurs in the condenser, it can be seen from Fig. 9 that the refrigerant at point 4 is still in the superheated gas, therefore the liquid phase of refrigerant does not occur as expected at the ideal T-s diagram. The initial refrigerant temperature enters the condenser is $65^{\circ} \mathrm{C}$ and the final refrigerant temperature is $50^{\circ} \mathrm{C}$, so that the condenser does not work effectively.

\section{Conclusions}

An exergy analysis was conducted for a recycle and recovery machine. Based on exergy analysis on the performance of recycling and recovery machine, the following can be concluded:

a. The highest destruction of exergy occurs at the compressor and then on the condenser. The destruction occurred because the irreversibility in the form of friction at the compressor and heat transfer that occurs in the condenser. The exergy destruction in the oil separator is very small.

b. The average of the exergy destructions are as follow: $59.98 \%$ occurs at the compressor, $14.643 \%$ at the oil separator, and $25.37 \%$ at the condenser.

c. The highest rate of exergy change occurs at the beginning of the process and dropped in the middle of the process and go up again at the end of the process

d. The value of RTR is $34 \mathrm{~g}$, while according to Standard 740 RTR the value must be less than $50 \mathrm{~g}$ so that the recycle and recovery machine already compatible with the standard for Residual Trapped Refrigerant (RTR). For the calculation, the value of Refrigerant Loss (RL) obtained is $10 \mathrm{~g}$ while according to AHRI Standard 740 the value can be as large as $15 \mathrm{~g}$ so that the recycle and recovery machine already compatible with the standards for grades Refrigerant Loss (RL).The performance of the recycle and recovery machine is equal to $92.1 \%$.

e. In accordance to the standards of the AHRI 740, that RTR required is $50 \mathrm{~g}$. Based on the experimental results, the RTR was reached at 50 seconds, therefore recovery is enough for 510 seconds, because after 510 seconds of exergy destruction increases again.

f. The real T-s diagram for the $2 R$ machine is very different from its ideal T-s diagram, therefore to have a good $2 R$ machine, a calculation for a design of $2 R$ machine should be done based on the unsteady process.

\section{Acknowledgments}

The financial support by the Indonesian government through program Hibah Kompetisi Dikti is acknowledged.

\section{REFERENCES}

AHRI Standard 740-98, 2015. Performance rating of refrigerant recovery equipment and recovery/recycling equipment, USA. Retrieved from http://www.ahrinet.org/App_Content/ahri/ files/standards\%20pdfs/AHRI\%20standards\%20pdfs/ AHRI_Standard_740-2015.pdf. (Accessed 20 December 2016).

Bejan, A., Tsatsaronis, G., Moran, M., 1996. Thermal Design \& Optimization. John Wiley \& Sons, Inc, Canada.

Cengel, Y.A., Boles, M.A., 2006. Thermodynamics: An Engineering Approach, fifth ed. McGraw-Hill, Boston.

Fang, G., Xing, L., Yang, F., Li, H., 2004. Exergy analysis of a dual-mode refrigeration system for ice storage air conditioning. International Journal on Architectural Science 6 (1), 1-6. 2005. Retrieved from: http://www.bse .polyu.edu.hk/researchCentre/Fire_Engineering/summary_of _output/journal/journal_AS.html.

Holman, J.P., 1997. Heat Transfer, 10th. McGraw-Hill Companies, Inc, New York.

Jain, N., Alleyne, A., 2015. Exergy-based optimal control of a vapor compression system. Energy Convers. Manag. 92 (2015), 353365. https://doi.org/10.1016/j.enconman.2014.12.014.

Moran, M.J., Shapiro, H.N., 2006. Fundamental of Engineering Thermodynamics, fifth ed. John Wiley \& Sons Ltd, England.

Padilla, M., Revellin, R., Bonjour, J., 2010. Exergy analysis of R413A as replacement of R12 in a domestic refrigeration system. Energy Convers. Manag. 51 (2010), 2195-2201. https://doi.org/ 10.1016/j.enconman.2010.03.013.

Pasek, A.D., Tandian, N.P., Adriansyah, W., 2004. Training of trainers mobile air conditioning sub-sector. Indonesia: the National plan for phasing out the use of CFC-12 in the Mobile Air Conditioning (MAC) sector project, OTF grant no. TF 021982; InstitutTeknologi Bandung, Ministry of Environmental Republic of Indonesia, The World Bank.Jakarta 6 - 10 September.

Yataganbaba, A., Kilicarslan, A., Kurtbas, I., 2015. Exergy analysis of R1234yf and R1234ze as R134a replacements in a two evaporator vapour compression refrigeration system. Int. J. Refrigeration 60 (2015), 26-37. https://doi.org/10.1016/ j.ijrefrig.2015.08.010.

Zoori, H.A., Farshad, S.F., Faramarz, S., Fazlollah, H., 2013. Comparison between energy and exergy efficiencies in a weir type cascade solar still. Desalination 325 (2013), 113-121. doi:10.1016/j.enconman.2016.11.044. 